\title{
Treatment of Malignant Glioma with High Dose Intra-arterial ACNU and Autologous Bone Marrow Transplantation - Case Report-
}

\author{
Takashi FUJIWARA, Junji YoshIOKA and Takashi OHмото
}

Department of Neurological Surgery, Kagawa Medical School, Kagawa

\begin{abstract}
A 44-year-old female with malignant astrocytoma received subtotal removal and high dose (200 mg/ $\mathrm{m}^{2}$ ) intra-arterial 1-(4-amino-2-methyl-5-pyrimidinyl)methyl-3-(2-chloroethyl)-3-nitrosourea hydrochloride (ACNU) with autologous bone marrow transplantation. Tumor remission with minimal bone marrow suppression was achieved. However, she developed severe encephalopathy and computed tomographic scans revealed a low-density area at the ACNU delivery site. She received glycerol solution to treat the brain edema and recovered completely from the encephalopathy. Intra-arterial ACNU exceeding $200 \mathrm{mg} / \mathrm{m}^{2}$ possibly causes neurotoxicity.
\end{abstract}

Key words: intra-arterial chemotherapy, ACNU, brain neoplasms, malignant astrocytoma, autologous bone marrow transplantation

\section{Introduction}

Nitrosoureas are currently the most effective agents for brain tumor chemotherapy. The effects, however, are still limited and often disappointing. ${ }^{11,12)}$ The relative ineffectiveness of brain tumor chemotherapy is probably at least partly due to the difficulty in achieving effective drug concentrations in tumor tissue by intravenous administration.

Recently, high dose intra-arterial or intravenous chemotherapy has achieved sufficient drug concentration in the tumor tissue. ${ }^{1.8,(0,14)}$ Intra-arterial administration is considered superior to intravenous administration because of reduced systemic toxicity and higher drug delivery to the tumor. However, nervous tissue tolerance and toxicity to intra-arterial chemotherapy are still unclear.

We report a case of malignant astrocytoma which definitely improved but developed severe associated encephalopathy after high dosage intra-arterial administration of 1-(4-amino-2-methyl-5-pyrimidinyl) methyl-3-(2-chloroethyl)-3-nitrosourea hydrochloride (ACNU).

Received November 16,$1990 ; \quad$ Accepted February 6, 1991

\section{Case Report}

A 44-year-old female complained of headache in September, 1986. She developed right hemiparesis with vomiting in December.

At admission on January 23, 1987, pre- and postcontrast computed tomographic (CT) scans revealed an enhanced mass lesion in the left frontal lobe (Fig. 1A). Angiography showed blood supply from the left middle and anterior cerebral arteries. The mass was subtotally removed on February 2 . Histological examination revealed a glial tumor with increased cellularity and moderate anaplasia (Fig. 2). No necrosis was evident. The diagnosis was malignant astrocytoma. Postoperative pre- and postcontrast CT scans revealed a residual tumor $1 \mathrm{~cm}$ in diameter in the deep frontal lobe (Fig. 1B).

On February 17, $3 \times 10^{8} / \mathrm{kg}$ of bone marrow cells were aspirated and frozen at $-70^{\circ} \mathrm{C}$. On February 22, a catheter was introduced via the common carotid artery into the supraophthalmic portion of the left internal carotid artery. ACNU (200 $\mathrm{mg} / \mathrm{m}^{2}$ ) was given over 30 minutes intra-arterially. One hour later she complained of nausea and vomited several times. However, no neurological deficits were noted. The bone marrow was injected intra- 

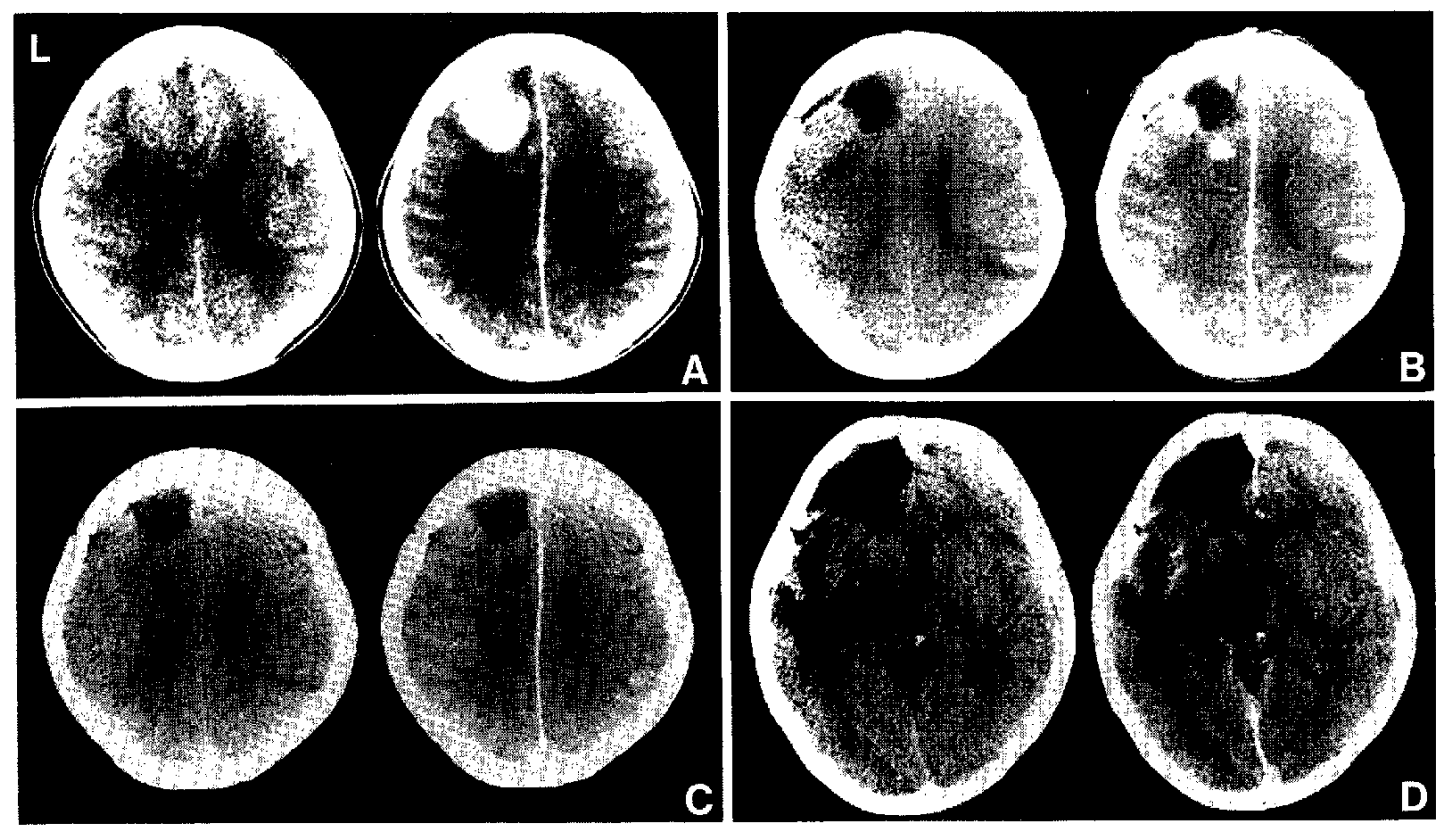

Fig. 1 Serial pre- (lefl) and postcontrast (right) CT scans. A: Preoperative CT scans showing an enhanced mass lesion with perifocal edema in the left frontal lobe. B: CT scans taken 10 days postoperatively, revealing the residual tumor $1 \mathrm{~cm}$ in diameter in the deep frontal lobe. $\mathrm{C}: \mathrm{CT}$ scans taken 5 weeks after ACNU chemotherapy, demonstrating complete tumor disappearance. D: CT scans taken 3 months after ACNU administration, showing a low-density area extending from the left temporal lobe to the left thalamus with a slight midline shift.

venously on February 25.

A complete blood cell count was taken at regular intervals. The platelet count began to decrease on March 4. On March 6, the granulocyte count began to decrease. On March 16, the platelet and

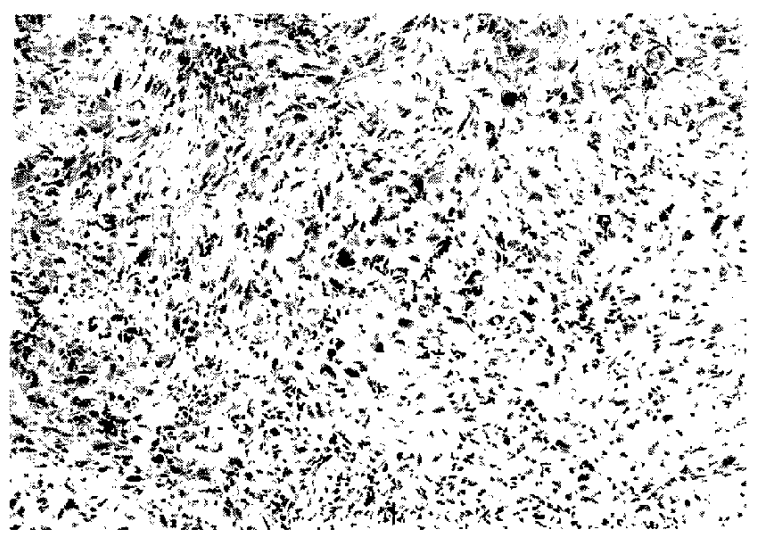

Fig. 2 Photomicrograph showing increased cellularity and moderate anaplasia in a reticular network of glial processes. No necrosis is seen. Histological diagnosis is malignant astrocytoma. granulocyte counts reached the minimum values of $1.7 \times 10^{4} / \mathrm{mm}^{3}$ and $400 / \mathrm{mm}^{3}$, respectively. A total of 30 units of platelets was administered and then recovered to normal levels by March 31 . She was treated in a semi-clean room during the 3 weeks when the granulocyte count was below $500 / \mathrm{mm}^{3}$ (Fig. 3).

Serial CT scans were carried out every 2 weeks,

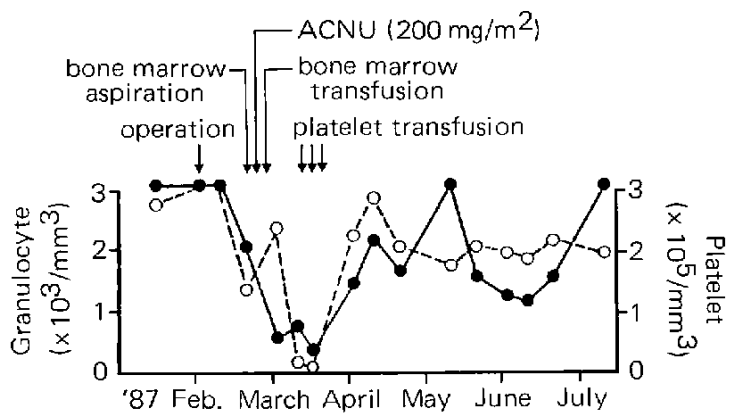

Fig. 3 Changes in granulocyte $(\bullet)$ and platelet $(0)$ counts following intra-arterial ACNU chemotherapy and autologous bone marrow transplantation. 
which showed the residual tumor had disappeared on March 26 (Fig. 1C). A sudden onset of recent memory disturbance and incomplete sensory aphasia occurred on May 18. CT scans revealed a low-density area extending from the left temporal lobe to the left thalamus with a slight midline shift to the right (Fig. 1D). The diagnosis was encephalopathy resulting from intra-arterial ACNU treatment. She received $400 \mathrm{ml}$ of $10 \%$ glycerol solution daily to treat the brain edema. The symptoms were worst 1 month later and then gradually improved. On June 29, a small enhanced lesion reappeared in the same location as the residual tumor. A tumor recurrence was diagnosed. The tumor disappeared again after $50 \mathrm{~Gy}$ of local irradiation. The low-density area on CT scans disappeared by July 27 . The original symptoms then recovered.

She now receives $300 \mathrm{mg}$ Tegaful daily and $3 \times 10^{6}$ IU $\beta$-interferon twice a week as maintenance therapy. She has been leading a normal daily life for 3 months with no neurological abnormality or recurrence on CT scans.

\section{Discussion}

Intra-arterial $\mathrm{ACNU}$ administration is preferable to intravenous administration for malignant brain tumors because: 1) ACNU delivery to tumor tissue is significantly greater when given intra-arterially, ${ }^{\text {") }} 2$ ) a high-peak concentration is more important than prolonged low-level exposure to anti-tumor action," 3) the biological half life of ACNU in vivo is relatively short (about 30 minutes), ${ }^{4}$ 4) glioma is usually located in the territory of one or two easily accessible arteries.

Glioma is suitable for autologous bone marrow transplantation since: 1) patients with glioma are relatively young, and so transplantation is easy, 2) glioma does not usually metastasize to bone marrow, 3 ) bone marrow suppression is a dose-limiting factor in nitrosourea chemotherapy, 4) high-dose nitrosourea, which almost completely suppresses bone marrow, is necessary to affect glioma cells.

Intra-arterial nitrosourea chemotherapy for metastatic and primary brain tumors has been investigated clinically. ${ }^{1,3,6,10,13,14)}$ Madajewicz et al. ${ }^{6}$ reported six complete and five partial remissions among 33 evaluable patients with metastatic brain tumor receiving $100 \mathrm{mg} / \mathrm{m}^{2}$ intra-arterial $\mathrm{BCNU}$. Greenberg et al." reported nine diminished tumors among 36 patients with malignant glioma after 2-7 courses of $200-300 \mathrm{mg} / \mathrm{m}^{2}$ intra-arterial BCNU. Yamashita et al. ${ }^{14)}$ reported 17 glioblastoma patients receiving $\mathrm{ACNU}$, eight intravenously and nine intra- arterially. The median survival time for the intraarterial group was significantly longer. However, a recent randomized trial by the Brain Tumor Cooperative Study Group on patients with malignant glioma showed survival for the intravenous and intra-arterial chemotherapy groups to be essentially the same. ${ }^{i 01}$

The major side effects caused by intra-arterial nitrosourea administration are central neurotoxicity such as convulsion, impaired consciousness, and focal neurological abnormalities. Eight to $19 \%$ of patients receiving $200 \mathrm{mg} / \mathrm{m}^{2}$ BCNU developed encephalopathy appearing on CT scans as lowdensity areas with mass effects.")

We administered $200 \mathrm{mg} / \mathrm{m}^{2}$ ACNU for left frontal malignant astrocytoma, which resulted in tumor disappearance. Possibly the intra-arterial ACNU chemotherapy alone was responsible. However, the tumor recurred 4 months later. Therefore, intraarterial chemotherapy is effective for malignant gliomas although the dose $\left(200 \mathrm{mg} / \mathrm{m}^{2}\right)$ is not sufficient for long term remission.

In our patient, bone marrow suppression was reduced by autologous bone marrow transplantation. However, severe encephalopathy developed later. Although the patient recovered from this, intra-arterial ACNU doses exceeding $200 \mathrm{mg} / \mathrm{m}^{2}$ may possibly cause brain cell injury.

Neurotoxicity may be caused by the alcohol in the BCNU infusate. ${ }^{1,2,5}$ Intra-arterial ACNU is water soluble and contains no alcohol, but still caused similar encephalopathy. Therefore, the drug probably causes the neurotoxicity.

High dose intra-arterial chemotherapy with autologous bone marrow transplantation is an effective treatment without severe systemic toxicity. However, the brain can only tolerate a certain drug concentration. The effectiveness and optimum dosage, schedule, and possible combination with other anti-cancer agents should be investigated.

\section{References}

1) Greenberg HS, Ensminger WD, Chandler WF, Layton PB, Junck L, Knake J, Vine AK: Intraarterial BCNU chemotherapy for treatment of malignant gliomas of the central nervous system. $J$ Neurosurg 61: 423-429, 1984

2) Greenberg HS, Ensminger WD, Seeger JF, Kindt GW, Chandler WF, Doan K, Dakhil SR: Intraarterial BCNU chemotherapy for the treatment of malignant gliomas of the central nervous system: A preliminary report. Cancer Treat Rep 65: 803-810, 1981

3) Hochberg FH, Pruitt AA, Beck DO, DeBrun G, 
Davis $\mathrm{K}$ : The rationale and methodology for intraarterial chemotherapy with BCNU as treatment for glioblastoma. J Neurosurg 63: 876-880, 1985

4) Hori T, Muraoka K, Saito Y, Sasahara K, Inagaki $H$, Inoue Y, Adachi S, Anno Y: Influence of modes of ACNU administration on tissue and blood drug concentration in malignant brain tumors. $J$ Neurosurg 66: $372-378,1987$

5) Layton PB, Greenberg HS, Stetson PL, Ensminger WD, Gyves JW: BCNU solubility and toxicity in the treatment of malignant astrocytomas. $J$ Neurosurg 60: 1134-1137, 1984

6) Madajewicz S, West CR, Park HC, Ghoorah J, Avellanosa AM, Takita $H$, Karakousis C, Vincent R, Caracandas J, Jennings E: Phase II study: Intraarterial BCNU therapy for metastatic brain tumors. Cancer 47: 653-657, 1981

7) Mahaley MS Jr, Whaley RA, Blue M, Bertsch L: Central neurotoxicity following intracarotid BCNU chemotherapy for malignant gliomas. I Neurooncol 3: 297-314, 1986

8) Phillips GL, Wolff SN, Fay JW, Herzig RH, Lazarus HM, Schold C, Herzig GP: Intensive 1,3-bis(2chloroethyl)-1-nitrosourea (BCNU) monochemotherapy and autologous marrow transplantation for malignant glioma. J Clin Oncol 4: 639-645, 1986

9) Rosenblum ML, Gerosa MA, Dougherty DV, Wilson CB: Improved treatment of a brain-tumor model. Part 1: Advantages of single- over multiple-dose BCNU schedules. J Neurosurg 58: 177-182, 1983

10) Shapiro WR, Green SB: Letters to the editor: Reevaluating the efficacy of intra-arterial BCNU. $J$
Neurosurg 66: 313-315, 1987

11) Takakura $K$, Abe $H$, Tanaka R, Kitamura $K$, Miwa T, Takeuchi K, Yamamoto S, Kageyama N, Handa $\mathrm{H}$, Mogami H, Nishimoto A, Uozumi T, Matsutani M, Nomura K: Effects of ACNU and radiotherapy on malignant glioma. J Neurosurg 64: 53-57, 1986

12) Walker MD, Green SB, Byar DP, Alexander E Jr, Batzdorf U, Brooks WH, Hunt WE, MacCarty CS, Mahaley MS Jr, Mealey J Jr, Owens G, Ransohoff J II, Robertson JT, Shapiro WR, Smith KR Jr, Wilson CB, Strike TA: Randomized comparisons of radiotherapy and nitrosoureas for the treatment of malignant glioma after surgery. $N$ Engl $\mathrm{J} \mathrm{Med} \mathrm{303:}$ $1323-1329,1980$

13) West CR, Avellanosa AM, Barua NR, Patel A, Hong $\mathrm{CI}$ : Intraarterial 1,3-bis(2-chloroethyl)-1-nitrosourea (BCNU) and systemic chemotherapy for malignant gliomas: A follow-up study. Neurosurgery 13: 420426,1983

14) Yamashita J, Handa $\mathrm{H}$, Tokuriki Y, Young SH, Otsuka S, Suda K, Taki W: Intra-arterial ACNU therapy for malignant brain tumors. Experimental studies and preliminary clinical results. $J$ Neurosurg 59: $424-430,1983$

Address reprint requests to: T. Fujiwara, M.D., Department of Neurological Surgery, Kagawa Medical School, 1750-1 Ikenobe, Miki-cho, Kita-gun, Kagawa 761-07, Japan. 